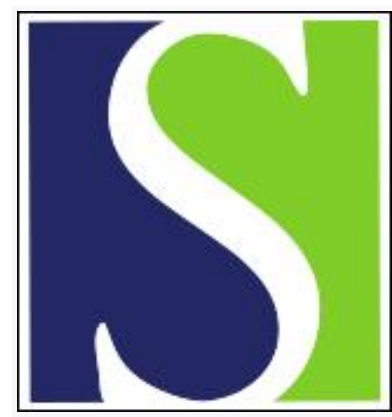

Scand J Work Environ Health 2008;34(3):213-223

https://doi.org/10.5271/sjweh.1226

Issue date: 30 Jun 2008

A diary study to open up the black box of overtime work among university faculty members

by Beckers DGJ, van Hooff MLM, van der Linden D, Kompier MAJ, Taris TW, Geurts SAE

Affiliation: Department of Work and Organizational Psychology, Behavioural Science Institute, Radboud University Nijmegen, PO Box 9104, NL-6500 HE Nijmegen, Netherlands. d.beckers@psych.ru.nl

Refers to the following texts of the Journal: 2003;29(3):171-188 2005;31(5):329-335 2006;32(6):502-514 2007;33(1):37-44 2006;32(6):421-430 2006;32(6):482-492 2006;32(4):318-327 2006;32(6):493-501 2006;32(6):473-481

The following articles refer to this text: 2011;37(5):418-426; 2018;44(3):239-250

Key terms: black box; diary study; overtime work; university faculty member; well-being; workhours; worktime control

This article in PubMed: www.ncbi.nlm.nih.gov/pubmed/18728911 


\title{
A diary study to open up the black box of overtime work among university faculty members
}

\author{
by Debby GJ Beckers, MA, ${ }^{1}$ Madelon LM van Hooff, PhD, ${ }^{1,2}$ Dimitri van der Linden, PhD, ${ }^{1}$ Michiel AJ \\ Kompier, PhD, ${ }^{1}$ Toon W Taris, PhD, ${ }^{1}$ Sabine AE Geurts, PhD ${ }^{1}$
}

Beckers DGJ, van Hooff MLM, van der Linden D, Kompier MAJ, Taris TW, Geurts SAE. A diary study to open up the black box of overtime work among university faculty members. Scand J Work Environ Health. 2008;34(3):213223

Objectives This study aimed at opening up the black box of overtime work among university faculty members by providing information on (i) when faculty members work overtime, (ii) what activities are undertaken during overtime, and (iii) how overtime is experienced.

Methods Data were collected among 120 Dutch faculty members who completed a general questionnaire (addressing general overtime hours, work characteristics, and well-being) and a 9-day diary study (with information on daily overtime hours, activities, and experiences). Analyses of variance were used to analyze the data.

Results Overtime was very prevalent among faculty members, high overtime workers being nonfatigued, engaged employees with positive work characteristics. Overtime was unevenly distributed over the week, being common on Sunday and Monday and uncommon on Friday and Saturday. Overtime activities during the weekend differed from those during the workweek, relatively much time being spent on research during weekend overtime. Overtime activities were experienced differently than activities during regular hours, overtime work being experienced as less effortful and less stressful than regular workhours and weekend overtime being less pleasurable than regular hours and evening overtime.

Conclusions This detailed day-to-day mapping and evaluation of overtime work contributes to a better understanding of overtime work by demonstrating meaningful patterns of overtime over the (work)week and meaningful associations between overtime activities and time-contingent experiences. It is suggested that worktime control plays an important role in explaining the results.

Key terms well-being; workhours; worktime control.

Studies on worktime have shown that overtime is a common phenomenon in today's industrialized countries. In Europe, $20 \%$ of employees work $\geq 45$ hours a week, and about $13 \%$ of the full-timers even worked $\geq 51$ hours a week (1). Long workhours are also widespread in the United States (US) in that more than one-fourth of US men and $11 \%$ of US women work >50 hours a week (2). Moreover, extreme overtime is pervasive in Korea and Japan, as many employees from these countries work $>60$ hours a week $(3,4)$.

This high prevalence has made overtime and its potential consequences for health and well-being a major research topic. Initially, overtime was mainly studied as a one-dimensional variable, and most studies basically investigated the simple, direct association between overtime and health or well-being $(5,6)$. Most of these studies thus treated overtime as a "black box".

Perhaps not surprisingly, this focus upon crude correlations did not result in a clear picture of the relationship between the number of hours worked and employees' health and well-being. Whereas many studies indicated that working long hours is associated with fatigue, a higher risk of injury, and (psycho)somatic health complaints (5, 7-9), other studies characterized overtime workers as nonfatigued and motivated employees (10, 11). These contradictory findings demonstrate that there is no simple, straightforward relationship between overtime and health, and it has been argued that the effects of overtime may depend on factors such as job content, the work environment, employee worktime control, motives

1 Radboud University Nijmegen, Behavioural Science Institute, Nijmegen, Netherlands.

2 TNO Quality of Life, Hoofddorp, Netherlands.

Correspondence to: Debby Beckers, Department of Work and Organizational Psychology, Behavioural Science Institute, Radboud University Nijmegen, PO Box 9104, NL-6500 HE Nijmegen, Netherlands. [E-mail: d.beckers@psych.ru.nl] 
for working overtime, and personal characteristics such as work motivation $(12,13)$.

One way to better understand the complex overtime-health association is by studying the influence of such potential moderators (14-16). For example, Tucker \& Rutherford (14) found that overtime work was only related to impaired health when schedule autonomy and social support were lacking. Moreover, Van der Hulst and her colleagues (16) showed that moderate overtime hours were only related to fatigue in case of high job demands in combination with low autonomy. Such studies are valuable and constitute an improvement over traditional "black box" studies, but they also incorporate some limitations. First, they build on cross-sectional designs that prohibit causal inferences between work characteristics, overtime, and positive and negative indicators of health and well-being. Second, they concentrate on general measurements of overtime hours, work characteristics, and indicators of health and well-being (ie, on global assessments of the usual state of affairs over a longer period of time, often the last couple of months). Therefore, it is still difficult to understand what exactly overtime implies on a daily, momentary basis.

We argue that, for the meaning of overtime to be understood, it is important to develop a more-detailed work psychological picture of overtime in daily life. A more fine-grained day-to-day analysis of overtime in its natural context may provide insight into some fundamental issues. First, earlier studies have provided general figures with respect to the prevalence of overtime (9), but little is known as to exactly when overtime takes place (ie, how overtime is distributed over the workweek and the weekend). Still, such detailed information can be crucial when the aim is to obtain insight into the overtime-well-being association. The effort-recovery model $(17,18)$ posits that too much effort investment, combined with too little recovery, will result in fatigued employees. According to this theory, overtime workers run the risk of becoming fatigued, as overtime extends the time that an employee has to invest effort and, at the same time, reduces the time left for recovery. Yet the balance between effort and recovery obviously not only depends on the total number of overtime hours a week, but also on the distribution of overtime hours over the workweek. Insight into the temporal pattern of overtime work will therefore lead to a better understanding of the association between actual overtime on one hand and fatigue and time-contingent positive (eg, pleasure) or negative affect (eg, stress) on the other. Second, although some authors roughly studied the overtime-work characteristics relationship $(10,16)$, it is as yet unknown exactly what it is that overtime workers do when they work overtime [ie, whether they conduct comparable activities during overtime hours as during regular workhours (more of the same) or whether different activities are carried out]. Finally, although many studies have concentrated on the relationship between overtime and general indicators of health and well-being $(5,6,19)$, these studies did not differentiate feelings and experiences during regular workhours from those during overtime. Therefore, it is still unknown how precisely overtime relates to time-contingent mood states. For example, it is not clear whether overtime during evenings (Monday-Friday) is rated differently (in terms of pleasure, effort, and stress) than overtime during the weekend.

This study takes a more fine-grained approach in order to provide insight into such issues. It uses a diary design, as diaries allow participants to describe their precise activities and psychological reactions on a dayto-day basis and at particular times $(20,21)$. Through this method, it is possible to assess the mood states and activities of participants shortly after they actually conducted their (overtime) work activities. In this manner, retrospection is minimized, and therefore so are the effects of recall bias (20).

A study sample with many overtime workers, high worktime control, and job variety is needed when whether overtime work varies over the workweek and whether activities during overtime hours differ from those during regular hours are examined. Our study was therefore conducted among a sample in which these work characteristics were assumed to be common, namely, Dutch university faculty members. This group's work activities can be divided into the following two important categories: (i) tasks related to research and (ii) tasks related to teaching.

The aim of our study was to open up the black box of overtime among Dutch faculty members and develop a detailed mapping and evaluation of overtime and its correlates "in vivo". In doing so, we aimed at a better insight into the work psychological meaning of overtime among these workers. More in particular, we set out to answer the following three research questions: (i) when: do the number of overtime workers and the number of overtime hours vary over the course of a workweek; (ii) what: do activities during overtime differ from activities during regular workhours; and (iii) how: is work during overtime rated differently than work during regular hours in terms of pleasure, effort, and stress?

\section{Study population and methods}

\section{Study population and procedure}

The participants in this study comprised faculty members who worked at a medium-sized university in the 
Netherlands. As the data of our study were collected as part of studies focusing on the work-nonwork interface of academics $(22,23)$, of 696 tenured employees who worked at least 3 days a week, only those were allowed to participate who (i) did not have a job outside the university and (ii) lived together with a partner who worked at least 2.5 days a week. Due to strict privacy regulations, it remained unknown how many of the employees who were initially approached for participation in the study actually met our inclusion criteria (ie, had no job outside the university and lived together with a partner who worked at least 2.5 days a week). A total of 146 employees agreed to participate, and of these persons 133 completed a general questionnaire (91\% response) assessing work characteristics, personal characteristics, and well-being. Data from 13 participants were removed as they did not meet the second inclusion criterion. Hence the final sample comprised 120 articipants, of which $62 \%$ was male, and the mean age was 45.2 years. The participants worked an average of 34.2 hours on contract 53 participants had a full-time contract (38-40 contractual workhours a week) and 67 worked part-time (24-37 contractual hours a week]. Still, most of the part-timers $(\mathrm{N}=40)$ reported having a substantial number of contractual workhours (32-37 hours/week). Most of the participants held doctorates and performed both research and teaching-related tasks. Altogether $46 \%$ worked as an assistant professor (lowest in $\mathrm{PhD}$ hierarchy), 17\% were associate professors, and $11 \%$ had a full professorship (highest in $\mathrm{PhD}$ hierarchy). The remaining $26 \%$ had other jobs, such as researcher or lecturer.

Ten days after completing the general questionnaire, the participants filled out short (diary) questionnaires, over a period of nine consecutive days (Saturday1, Sunday1, Monday-Friday, Saturday2, Sunday2). We carefully planned the timing of (the diary part of) the study to obtain a standard workweek (eg, no holiday period just before, after, or during the nine days under study). The diary questionnaires had to be completed three times a day: (i) a morning questionnaire (to be completed after waking up in the morning, between 0730 and 0830), (ii) an afternoon questionnaire (to be completed at approximately 1800), and (iii) an evening questionnaire (to be completed before going to sleep, between 2200 and 2300). Altogether 120 respondents took part in the diary part of the study. Only the diary questionnaires that were completed at or around the requested time were included in our study. Morning questionnaires were removed when they were completed more than 2 ours after awakening; afternoon questionnaires were excluded when they were completed before 1630, after 2000 , or less than 3 hours after the morning questionnaires; finally, we removed evening questionnaires that were completed less than 2 hours after the afternoon questionnaire or after 0300 . This procedure resulted in $76.2 \%$ valid morning diaries, $73.4 \%$ valid afternoon diaries, and $72.5 \%$ valid evening diaries (the percentages were based on $\mathrm{N}=120$ participants $\times 9$ days).

\section{General questionnaire}

The answers from the general questionnaire were mainly used to provide a characterization of the average overtime worker in our sample.

Workhours. Overtime hours were assessed with the following item: "On the average, how many hours a week do you spend on overtime?" Regular workhours were measured using the item: "How many hours a week do you work on contract?"

Work characteristics. Job demands were measured with five items from the job content questionnaire (24) that were rephrased as questions. An exemplary item is "Do you have to work very fast?" [ $1=$ (almost) never, $4=($ almost) always; $\alpha=0.74]$. Job control was measured with six items from Van Veldhoven and his colleagues (25). The items measured control over job content (eg, "Can you determine the content of your job?"), as well as control over worktime (eg, "Can you take a short break when you feel it is necessary?"). The response categories for job control ranged from 1 to 4 [ $1=$ (almost) never, $4=$ (almost) always; $\alpha=0.67$ ].

Well-being. We used the 10-item fatigue assessment scale (26) to measure (general) fatigue. Two exemplary items are "I feel mentally exhausted" and "I feel physically exhausted" $[1=$ (almost) never, $5=$ (almost) always; $\alpha=0.86]$. Work engagement was assessed with five items adapted from Rothbard (27) (eg, "When I am working, I often lose track of time" [ $1=$ strongly disagree, $5=$ strongly agree; $\alpha=0.79]$. Home engagement was measured using 4 items (27). An exemplary item is "When I am with my partner or family, I often lose track of time" ( $1=$ strongly disagree, $5=$ strongly agree; $\alpha=0.71$ ).

\section{Diary measures}

For time spent daily on work activities, the participants received a list of 12 work activities and indicated the time $(0=$ none, $1=<1$ hour, $2=1-2$ hours, $\ldots 7=$ $>6$ hours) they had spent on each activity during regular workhours [ie, until 1800, afternoon questionnaire) and after 1800 (evening questionnaire)]. The range of time spent on the tasks was recoded to obtain an estimate of the actual time by assuming that the actual time spent on an activity would lie in the middle of the two 
extremes (eg, the category "1-2 hours" was recoded as "1.5 hours"). Time spent on research activities consisted of the time spent on "conducting research", "data analysis", "reading literature", and "writing papers". Time spent on teaching activities included time spent on "preparing a lecture", "giving a lecture", "reading (PhD) students' assignments", and "appointments with (PhD) students". Time spent on meetings consisted of the time spent on "preparing meetings" and "attending meetings". Finally, time spent on contacts included time spent on e-mails and informal contact with colleagues.

(Time spent on) overtime work was operationalized by summing the time spent on all 12 work activities after 1800 during weekdays (Monday through Friday) and the total time spent on work activities before and after 1800 during the weekend (Saturday and Sunday). As two weekends were included in the diary study, we computed the average time spent on work of both weekends to obtain a more-reliable measure of time spent on overtime work during the weekend.

(Time spent on work during) regular workhours was computed by summing the time spent on all 12 work activities before 1800 from Monday through Friday.

For work experiences the participants were requested, in the afternoon and evening questionnaires, to indicate the extent to which they considered the preceding (work)day (until 1800) and work activities in the evening (between 1800 and 2300) as pleasurable, effortful, and stressful ( 1 = not at all, $10=$ extremely). The average work-related pleasure during regular hours was computed by averaging the pleasure-report marks for worktime until 1800 from Monday through Friday. The same was done for the average work-related effort and work-related stress during regular workhours. The average work-related pleasure during overtime in the evening from Monday through Friday was computed by averaging the pleasure-report marks of the worktime in the evening (after 1800) from Monday through Friday. Again, the same was done for the average work-related effort and work-related stress during the evening overtime hours. The average work-related pleasure during overtime on the weekend was computed by averaging the pleasure-report marks of the worktime during the day (afternoon questionnaire) and during the evening (after 1800) from the four weekend days (two Saturdays and two Sundays). The same was done for the average workrelated effort and work-related stress during overtime on the weekend.

\section{Statistical analyses}

To obtain a basic understanding of our data, we first discuss the means and standard deviations for the full sample, as well as for the three overtime groups. On the basis of the diary reports of overtime hours, three overtime groups were construed using a tertile split: a no-low overtime group (0-2.9 overtime hours from Monday through Sunday, $\mathrm{N}=35$ ), a moderate overtime group (3-7.4 overtime hours from Monday through Sunday, $\mathrm{N}=35$ ), and a high overtime group ( $\geq 7.5$ overtime hours from Monday through Sunday, $\mathrm{N}=34$ ). The mean scores of these three groups on several work characteristics and indicators of well-being were compared using analyses of variance (ANOVA) with follow-up tests (Tukey's LSD tests). Chi-square tests were used to compare the groups with respect to categorical variables (gender and contract type).

Our first research question referred to the days on which faculty members work overtime. A 7 (day: Saturday, Sunday, ...., Friday) $\times 2$ (overtime: yes versus no) crosstable analysis was conducted to test whether the proportion of faculty members working overtime varied across the days of the week. Furthermore, we performed a one-factor analysis of variance (ANOVA with LSD posthoc tests) with day as the factor of interest to see whether the number of overtime hours worked varied across the days of the week. Note that this analysis was conducted using the days on which the faculty members worked overtime as the units of analysis, not the individual faculty members.

The second research question referred to the type of activities conducted during overtime and whether these activities differed from those conducted during regular workhours. We calculated the percentage of time spent on four types of work activities (teaching, research, meetings, contacts) during regular workhours, evening overtime, and weekend overtime.

Finally, our third research question pertained to how overtime work is experienced, as compared with work done during regular workhours. We compared four types of worktime with respect to work-related pleasure, work-related effort, and work-related stress: (i) regular workhours (Monday-Friday, work activities before 1800), (ii) weekday evening overtime work (Monday-Friday, after 1800), (iii) weekend overtime work during the day (before 1800), and (iv) weekend overtime during the evenings (after 1800). To examine whether the participants' scores on the three criterion variables varied according to the day of the week and the time of day, these data were analyzed in a 3 (type of experience: pleasure, effort, stress) $\times 2$ (day: weekday versus weekend) $\times 2$ (time: daytime versus evening) multiple analysis of variance (MANOVA) with "type of experience" and "time" as within-participants factors. To facilitate the interpretation of the effects, we conducted three separate follow-up ANOVA for each criterion variable.

Note that the participants could contribute data for all four combinations of "day" and "time", which implies that the observations for these categories were 
not statistically independent (28). To examine the magnitude of this dependence, we conducted six preliminary 2 (day: weekday versus weekend) $\times 120$ (participant 1 to 120) ANOVA [one for each combination of outcome (pleasure, effort, stress) and time point (daytime versus evening)], with "participant" as a random factor. These analyses revealed that, in all six cases, "participant" accounted for only a marginal proportion of the variance in the criterion variables (all $\mathrm{R}^{2}<0.05 \%$ ). Thus, for practical purposes, the statistical dependence among the observations can safely be ignored (29).

\section{Results}

\section{Preliminary analyses—descriptive statistics of the sample}

Table 1 shows that the prevalence of overtime work was high in our sample. In the general questionnaire, the mean number of overtime hours within the total sample was 7.36, and $94 \%$ of the participants reported having worked overtime. The diaries provided similar statistics. In the total sample, the average number of overtime hours during the assessed week was 6.02 , and $90 \%$ reported having worked overtime. Furthermore, the participants reported a reasonably high (but not excessive) level of general job demands (mean $=2.62 ; 2=$ sometimes and $3=$ often) and high general job control over worktime and job content $($ mean $=3.23 ; 3=$ often and $4=$ always). The participants' level of general fatigue was, on the average, low (mean $=1.89 ; 1=$ never fatigued and $2=$ sometimes fatigued), whereas their work and home engagement were high (the means of both types of engagement equaling almost 4 on a scale of $1-5)$.

To obtain more insight into the possible differences among the no-low, moderate, and high overtime workers, we compared these three diary-based overtime groups with respect to personal characteristics, general work characteristics, general fatigue, and general engagement. Table 1 shows that the high diary-overtime group differed significantly from the two other diary-overtime groups with respect to overtime hours as assessed with the general questionnaire (ie, the participants who reported a high number of overtime hours on a day-to-day basis also reported a high number of overtime hours in general). The low and moderate diary overtime groups did not differ significantly from each other with respect to overtime hours in the general questionnaire.

The overtime groups did not differ significantly with respect to gender distribution, age, job characteristics

Table 1. Descriptive statistics for the total sample and three overtime groups.

\begin{tabular}{|c|c|c|c|c|c|c|c|c|c|c|c|c|c|c|}
\hline \multirow[t]{3}{*}{ Dependent variables } & \multirow[t]{3}{*}{ Range } & \multirow{2}{*}{\multicolumn{3}{|c|}{ Total sample $(\mathrm{N}=120)$}} & \multicolumn{9}{|c|}{ Overtime group (diary measure) } & \multirow{3}{*}{$\begin{array}{l}\text { Results from the } \\
\text { statistical analysis }\end{array}$} \\
\hline & & & & & \multicolumn{3}{|c|}{ No or low $(\mathrm{N}=35)$} & \multicolumn{3}{|c|}{ Moderate $(\mathrm{N}=35)$} & \multicolumn{3}{|c|}{ High $(\mathrm{N}=34)$} & \\
\hline & & Mean & $\mathrm{SD}$ & $\%$ & Mean & SD & $\%$ & Mean & SD & $\%$ & Mean & SD & $\%$ & \\
\hline $\begin{array}{l}\text { Overtime hours } \\
\text { (diary measure) }\end{array}$ & $0-28.5$ & 6.02 & 5.32 & . & $1.06^{a, b}$ & 0.90 & . & $4.90^{\mathrm{b}, \mathrm{c}}$ & 1.23 & . & $12.28^{a, c}$ & 4.25 & . & $F(2,101) 167.43 ; P<0.001$ \\
\hline $\begin{array}{l}\text { Overtime hours } \\
\text { (general measure) }\end{array}$ & $0-30$ & 7.36 & 5.44 & . & $4.24^{b}$ & 2.85 & . & $6.54^{b}$ & 4.50 & . & $10.67^{a, c}$ & 6.72 & . & $F(2,98)$ 14.33; $P<0.001$ \\
\hline Contractual workhours & $24-40$ & 34.24 & 5.54 & . & 32.89 & 5.31 & . & 34.86 & 5.58 & . & 34.76 & 5.31 & . & $F(2,101) 1.48 ; P=0.23$ \\
\hline Job demands & $1-4$ & 2.62 & 0.40 & . & 2.51 & 0.40 & . & 2.69 & 0.39 & . & 2.59 & 0.40 & . & $F(2,101) 1.62 ; P=0.20$ \\
\hline Job control & $1-4$ & 3.23 & 0.43 & . & 3.24 & 0.41 & . & 3.29 & 0.36 & . & 3.19 & 0.48 & . & $F(2,101) 0.48 ; P=0.62$ \\
\hline Fatigue & $1-5$ & 1.89 & 0.59 & . & 1.89 & 0.63 & . & 1.83 & 0.47 & . & 2.03 & 0.68 & . & $F(2,101) 1.05 ; P=0.35$ \\
\hline Work engagement & $1-5$ & 3.95 & 0.70 & . & 3.74 & 0.77 & . & 3.89 & 0.75 & . & 4.14 & 0.58 & . & $F(2,100) 2.86 ; P=0.06$ \\
\hline Home engagement & $1-5$ & 3.59 & 0.72 & . & $3.84^{b}$ & 0.58 & . & 3.54 & 0.81 & . & $3.34^{c}$ & 0.80 & . & $F(2,101) 3.97 ; P=0.02$ \\
\hline Age & $31-63$ & 45.2 & 7.83 & . & 44.59 & 6.69 & . & 43.66 & 8.70 & . & 46.24 & 7.86 & . & $F(2,100) 0.96 ; P=0.39$ \\
\hline Gender & & & & & & & & & & & & & & $\begin{array}{l}\chi^{2}(\mathrm{df}=2, N=104) 1.18 \\
P=0.55\end{array}$ \\
\hline Male & .. & . & . & 61.7 & . & . & 54.3 & . & . & 65.7 & . & . & 64.7 & . \\
\hline Female &.. & . & . & 38.3 & . & . & 45.7 & . & . & 34.3 & . & . & 35.3 & . \\
\hline Contract type & & & & & & & & & & & & & & $\begin{array}{l}\chi^{2}(d f=2, N=104) 2.69 \\
P=0.26\end{array}$ \\
\hline Part-time & .. & . & . & 55.8 & . & . & 68.6 & . & . & 54.3 & . & . & 50 & . \\
\hline Full-time &.. & . & . & 44.2 & . & . & 31.4 & . & . & 45.7 & . & . & 50 & . \\
\hline
\end{tabular}

a Differs significantly from the respective value of the "moderate overtime group".

"Differs significantly from the respective value of the "high overtime group".

c Differs significantly from the respective value of the "no-low overtime group". 
(contractual workhours, demands, and control), or fatigue. For work engagement, the P-value was marginally significant $(\mathrm{P}=0.06)$, indicating a trend in which more overtime hours seem to coincide with higher work engagement. [See table 1 for the means.] There was a significant difference between the overtime groups as regards home engagement, indicating that employees in the low overtime group were more home-engaged than the employees in the high overtime group (table 1). Still, in absolute terms, the home-engagement level of the latter group was rather high (mean $=3.34$ on a 5-point scale).

In summary, the faculty members with many overtime hours worked in a psychosocial job environment that was similar to that of the faculty members with no or low overtime hours. This psychosocial job environment can be characterized as "active" according to the demand-control model of Karasek (30). The high overtime workers could not be characterized as fatigued employees, but rather as employees with relatively high work engagement and lower (but not low) home engagement.

\section{Research question 1: When: do the number of over- time workers and the number of overtime hours vary over the course of a workweek?}

The percentage of faculty members working overtime varied significantly over the course of the workweek, $\chi^{2}$ $(\mathrm{df}=6, \mathrm{~N}=840)=27.14 ; \mathrm{P}<0.001$ (figure 1). The number of participants working overtime was significantly higher on Sunday (57\% worked overtime) and Monday (58\%), and significantly lower on Friday (27\%) and Saturday $(37 \%)$ than on the remaining weekdays (specific P-values not shown but available on request from the first author).

In addition, our analyses revealed that the days differed with respect to the number of overtime hours, $\mathrm{F}(6,59)=11.72 ; \mathrm{P}<0.001$ (figure 2). Pairwise comparisons showed that the overtime workers in this study worked, on
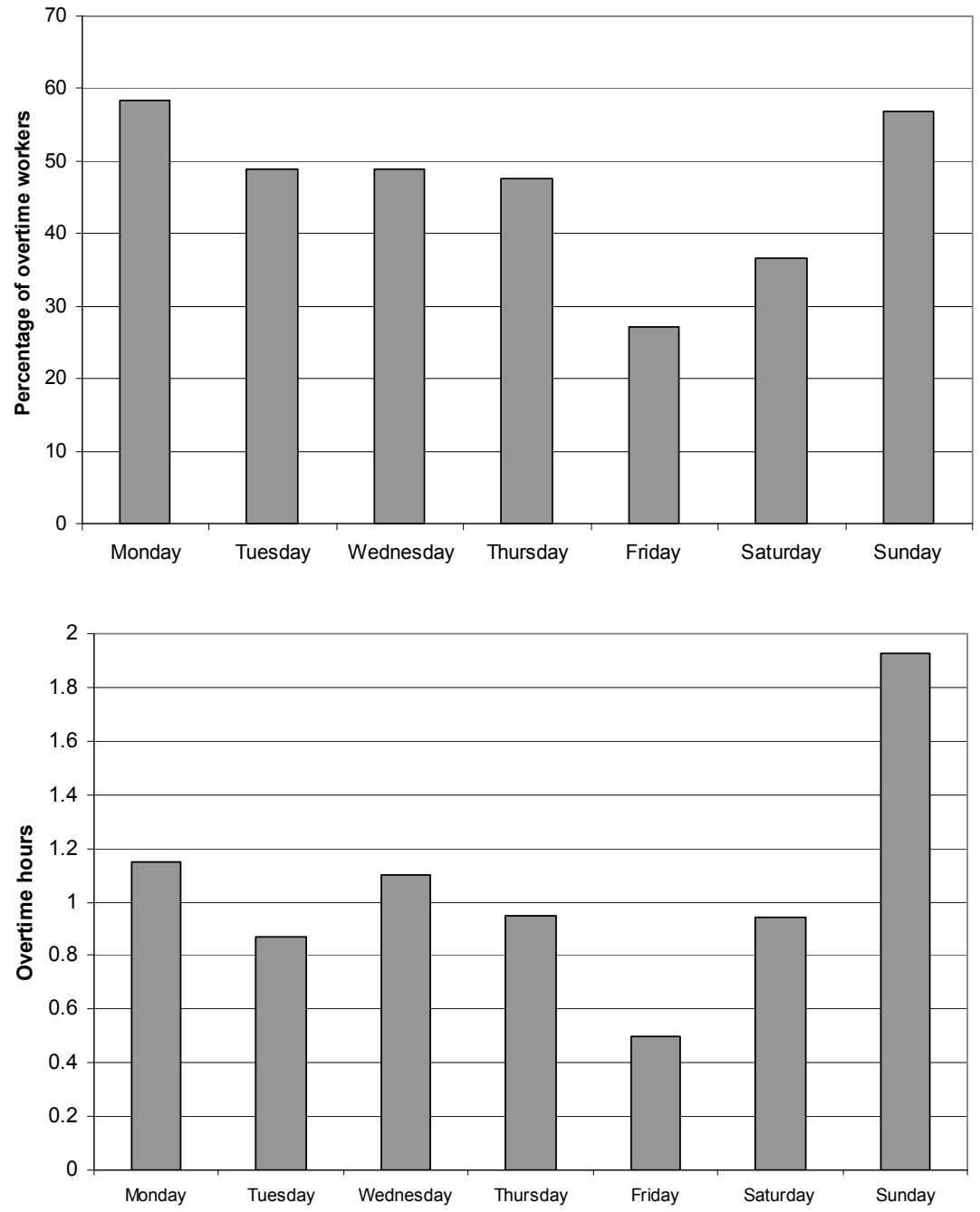

Figure 1. Percentage of overtime workers per day (within the total sample, $\mathrm{N}=120$ ). For weekend overtime, the average of two Saturdays and two Sundays was used.
Figure 2. Mean number of overtime hours per day (among the respondents who worked overtime on at least 1 day during the assessed 9 days and who had no missing value for overtime hours in the 9 days, $\mathrm{N}=65$ ). For weekend overtime, the average of two Saturdays and two Sundays was used. 
the average, relatively many overtime hours on Sunday (Sunday versus other days: $\mathrm{P}<0.05$ ) and a relatively low number of overtime hours on Friday (Friday versus other days: $\mathrm{P}<0.01)$. Figure 2 shows that the mean number of overtime hours (for those who worked overtime on at least one day during the measurement period) was almost 2 hours on Sunday, only 0.5 hours on Friday, and about 1 hour on the other days of the week.

Accordingly, the findings reported in figures 1 and 2 converge in that they show that the number of overtime workers and the number of overtime hours were relatively high at the beginning of the workweek and low at the end of the workweek. Moreover, many university faculty members worked relatively many overtime hours on Sunday.

\section{Research question 2: What: do activities during overtime hours differ from activities during regular workhours?}

Figure 3 shows the time (in percentages) spent on activities (teaching, research, meetings, contacts) during regular workhours, evening overtime, and weekend overtime work.

During regular hours, as well as during overtime hours, the participating faculty members spent about one-third of their time on teaching-related tasks. The participants spent more time on teaching than on research during regular workhours and evening overtime. In contrast, during weekend overtime work, the most prevalent category was "research". Relatively, time spent on research was lowest during regular workhours (mean $=26 \%$ of the regular hours), higher during evening overtime (mean $=32 \%$ of evening overtime), and highest during weekend overtime (mean $=43 \%$ of weekend overtime hours).

Apart from teaching and research activities, the faculty members also spent time on two other work

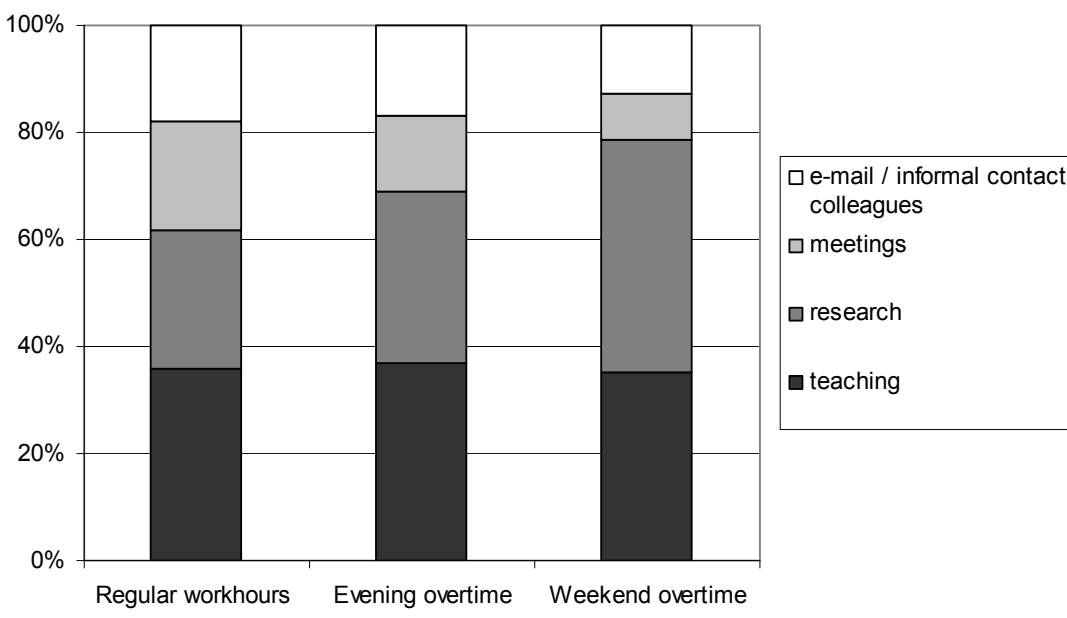

categories, namely, "preparing and attending meetings" and "e-mail and informal contact with colleagues". Obviously, the relative time spent on meetings was on the average highest during regular workhours and lowest during the weekend (figure 3). With respect to e-mail and informal contact with colleagues, figure 3 shows that the relative time spent on these activities was lowest during the weekend.

\section{Research question 3: How: Is work during overtime rated differently than work during regular hours in terms of pleasure, effort, and stress?}

A 3 (type of experience: pleasure versus effort versus stress) $\times 2$ (day: weekday versus weekend) $\times 2$ (time: daytime versus evening) MANOVA with "type of experience" and "time" as within-participant factors revealed a significant main effect for "day" $[F(1,232)=5.34$; $\mathrm{P}=0.02]$ and a significant interaction effect for day $\times$ time $[F(1,231)=13.74 ; P<0.001]$. These findings indicate that the participants' scores varied significantly with "day" and "time" on at least one of the outcome variables. These effects are discussed separately for each of the three outcome variables: work-related pleasure, workrelated effort, and work-related stress.

Work-related pleasure. A 2 (day: weekday versus weekend) $\times 2$ (time: daytime versus evening) ANOVA with repeated measures on "time" showed a significant main effect for "day" $[\mathrm{F}(1,235)=4.02 ; \mathrm{P}=0.046]$. Work was rated as significantly less pleasurable during the weekend (mean $=6.06$ ) than on weekdays (Monday-Friday, mean $=6.48)$. This effect was not further qualified by "time" $[\mathrm{F}(1,235)=2.78 ; \mathrm{P}=0.10]$. Thus this study's faculty members rated their overtime work during the weekend as less pleasurable than work during weekdays (irrespective of whether it was conducted during regular workhours or in the evenings).
Figure 3. Relative time spent on different activities during regular workhours, evening overtime, and weekend overtime. For weekend overtime, the average of two Saturdays and two Sundays was used. 
Work-related effort. An ANOVA similar to that used for work pleasure was carried out for work effort. This analysis yielded a significant day $\times$ time interaction $[\mathrm{F}(1,235)=8.08 ; \mathrm{P}=0.005]$, which implied that effort investment depends on both the day on which the respondents work (weekdays versus weekend) and the time at which they work (daytime versus evening). Specifically, the three types of overtime were rated as less effortful ( mean $_{\text {weekend-daytime }}=4.52$, mean $n_{\text {weekend-evening }}$ $=4.67$, mean $_{\text {weekday-evening }}=4.60$ ) than regular workhours (work during daytime on weekdays, mean $=5.25$; all P-values <0.05).

Work-related stress. Finally, a day $\times$ time ANOVA on work stress showed a significant day $\times$ time interaction for stress $[\mathrm{F}(1,232)=5.51 ; \mathrm{P}=0.02]$. Overtime work was rated as relatively less stressful $\left(\mathrm{mean}_{\text {weekend-daytime }}=2.42\right.$, mean $_{\text {weekend-evening }}=2.25$, mean $n_{\text {weekday-evening }}=2.38$ ) than regular workhours $($ mean $=3.06 ; \mathrm{P}<0.05)$.

In summary, the mean scores for pleasure, effort, and stress showed that overtime work in this study was experienced as less pleasurable, but also as less effortful and less stressful than work during regular hours.

\section{Discussion}

A fine-grained analysis of overtime work was carried out by means of a diary study among university faculty members. Our aim was to open up the black box of overtime work in order to render a better understanding of overtime work in a natural context and its relationship to well-being.

Our general questionnaire revealed that the faculty members in our study worked in a favorable psychosocial work environment with high (worktime) control. The overtime workers among them (about 90\% of all the respondents) could not be characterized as fatigued employees, but rather as employees with relatively high work engagement. In the diary part of the study, the data revealed that overtime work was neither evenly distributed over the workweek nor over the weekend. There was a clear overtime pattern over the week with the highest number of overtime workers, as well as the highest number of overtime hours at the beginning of the week (Sunday, Monday) and the lowest numbers at the end of the week (Friday, Saturday). Although roughly the same basic work activities were undertaken during regular hours and overtime hours, the faculty members spent relatively much of their overtime work on research activities, especially during weekend overtime work. Apparently, the content of work-related activities differs between workdays and weekend days. Furthermore, the analyses revealed that the participants rated their overtime as less stressful and less effortful than work during regular workhours. This finding corresponds with findings from a study by Haugland (31), who found that stress levels of academic personnel were lower during evening overtime than during regular workhours. The participants of that study attributed this difference to the fact that overtime work permits uninterrupted and therefore efficient work. Finally, in our current study, weekend overtime was rated as less pleasurable than work from Monday through Friday, although, in absolute terms, it was not considered unpleasurable.

Several of these outcomes deserve to be further discussed, the first being the Monday-Friday distinction in overtime work. It is tempting to suggest that Monday is preferred for overtime activities because, at the start of the new week, employees are relatively well recovered. Building on the effort-recovery theory $(17,18)$, we can hypothesize that, during the course of the workweek, the need for recovery increases, and this phenomenon may explain why the participants seldom worked overtime on Friday evening. This explanation receives support from a recent study on overtime work among faculty members and other office workers by Dahlgren and her colleagues (32), who found that sleepiness (ie, the need to recover) was stronger at the end of the week. The temporal pattern of overtime work in our study may also partly be explained by commitments in the nonwork area (eg, social events) that are more common on Friday than on Monday. A second issue refers to the difference between Saturday and Sunday. We speculate that the lower prevalence of overtime on Saturday (36\%) stems from the aforementioned need for recovery in combination with tasks and obligations in private life (eg, chores, shopping). To our surprise, almost $60 \%$ of the participants did work on Sundays. Although speculative, we believe this high prevalence to originate from the "active" job profile of the faculty members in this study: high but not excessively high job demands (both regarding teaching and research), high control, and high work engagement. Because, during the regular workweek, teaching-related activities made up the dominant category and because teaching obligations can hardly be ignored, it may be difficult to meet high research demands during the regular workweek. The Sunday profile with much research may indicate an endeavor to keep up with high research standards. Of course, it can be argued that a utilitarian perspective might provide a more basic explanation (33). It would hold that academic staff might prefer to spend their weekends on activities that they enjoy the most (ie, research). However, the relatively restricted pleasure scores related to weekend overtime work do not make this a very plausible explanation.

We believe worktime control to be an important concept in explaining the findings of our study. Worktime control refers to the freedom to largely self decide 
the temporal conditions of work (9). University faculty members generally have high worktime control; therefore, within certain preset limits (the faculty members officially had to be at the office between 0930-1200 and 1400-1630), they can largely self-decide when to start work, when to take breaks, when to end their workday, when to take a day off or plan a holiday, and when to conduct particular work activities. In accordance, it seems plausible that faculty members also generally self-decide when to work overtime and for how long. They probably use their high worktime control to balance their effort and recovery, and they decide to stop working overtime before becoming too fatigued or stressed. This possibility would explain why overtime work is more common on Monday than on Friday, less common on Saturday than on Sunday, why excessive overtime occurs very seldom and moderate overtime (6 or 7 hours a week) is the norm, and why overtime is not related to fatigue or stress. Some recent studies indeed have found evidence for a buffering effect of high worktime control on stress, sickness absence, and worklife balance (34-38).

\section{Limitations and suggestions for future research}

We believe three limitations are worth discussing. First, our study employed a specific, homogeneous sample of university faculty members. In this sample, the work environment could be described as "active" in terms of Karasek's demand-control model (30) [ie, incorporating high job demands and high (worktime) control]. Therefore, our findings may well be relevant for other "active" jobs with high worktime control, but cannot automatically be generalized to professions with very different work characteristics. Therefore, it is useful to repeat this type of study in other samples with high worktime control and to also conduct future diary studies within high-strain or passive jobs (30) with low worktime control. In relation to the latter, attention should be paid to the experience of mandatory overtime work $(39,40)$.

Second, field studies are inevitably characterized by certain methodological restrictions. The fact that we did not know the actual response rate as a result of strict privacy regulations can be considered such a limitation of this study. It was not possible to examine the extent to which the participating faculty members formed a "nonrepresentative" selection of the total study population (eg, a relatively healthy or unhealthy subselection).

Finally, our definition of overtime work as "all work activities executed after 1800" may be questioned. It is possible that, for some employees, this point of time does not correctly reflect the transmission from regular workhours to overtime work. First, for part-timers, overtime work may have started before 1800 . However, including part-timers in our study did not influence our findings, as posthoc analyses with only the full-timers $(\mathrm{N}=53)$ showed similar results (results obtainable on request from the first author). Second, it can be argued that working after 1800 is still part of a person's regular workhours when he or she starts work after 0900. However, in our sample of part-timers and full-timers, the average worktime before 1800 is about 8 hours from Monday to Friday, and this length of time implies that it is not likely that many participants started their workday much later than 0900 . Finally, it can be argued that employees can also work overtime in the mornings before 0900. Previous studies indeed showed that overtime workers can report an earlier start of the workday during overtime periods $(32,41)$. Yet morning overtime work did not seem to be a common phenomenon in our sample, as the average time between waking up in the morning and leaving for work was 84 minutes. This time is less than 1.5 hours for morning activities like having breakfast, taking a shower, and (in case of the participants with children) making sure that children get ready for school or arrive at day care in time. Consequently, a potential bias because of "early bird overtime work" does not seem likely. Hence, although "work after 1800" is a proxi-operationalization and no perfect indicator of overtime work, we consider it to be a sufficiently valid operationalization for our sample. Nevertheless, future diary studies on overtime work should try to measure daily overtime work as accurately as possible. It would be advisable to let respondents report on a daily basis when they started and ended their "regular workhours", and exactly when they started working overtime and when they ended it. Such factual daily questions about regular workhours and overtime hours would provide a valid picture of daily overtime work.

Other suggestions may also be useful when future diary studies on overtime work are planned. First, our study only included (subjective) self-report measures (eg, of time-contingent mood and stress). In future studies, it would be interesting to also collect performance data (eg, for the current occupational group: the number of students supervised, the number of articles written, etc) and to collect information about the psychophysiological costs of work-related effort not only at work and during overtime, but also during recovery time. Regarding the latter, it would be interesting to also collect objective data on sleep quality and quantity (42). Moreover, it would also be interesting not only to examine work activities during regular hours and overtime hours, but also to use diary studies to examine overtime workers' (health-related) activities during leisure time [eg, the amount of exercise, alcohol consumption, and smoking (43)].

Another suggestion for future (diary) research on overtime work is to collect more-detailed information about the nature of overtime work (eg, whether it is 
voluntary or involuntary and whether it is compensated or not). Absence of this information in our current study may have complicated the interpretation of the findings to some extent, as these characteristics of overtime work can affect the stressfulness of working overtime $(15,44)$.

\section{Implications and concluding remarks}

Although not without limitations, we believe that this diary study rendered a better understanding of overtime work and its relation to well-being. In this study, no association was found between overtime work and fatigue. This finding can be explained by the meaningful patterns of overtime over the (work)week and meaningful associations between overtime activities and time-contingent experiences that emerged from our detailed mapping of overtime work. In turn, this distribution of overtime work over the workweek and positive evaluation of overtime work seems to be an outcome of high worktime control. Our results imply that moderate overtime does not have to be a problem among employees with high worktime control. A practical implication that follows from our study is that today's (flexible) worktime arrangements should be arranged in such a way that they provide enough worktime control for employees.

\section{References}

1. Paoli P, Merrlié D. Third European survey on working conditions 2000. Luxembourg: European Foundation for the Improvement of Living and Working Conditions; 2001.

2. Jacobs JA, Gerson K. The time divide: work, family, and gender inequality. Cambridge (MA): Harvard University Press; 2004. Cited in: Caruso CC. Possible broad impacts of long work hours. Ind Health. 2006;44:531-6.

3. Amagasa T, Nakayama T, Takahashi Y. Karojisatsu in Japan: Characteristics of 22 cases of work-related suicide. J Occup Health. 2005;47:157-64.

4. Uehata T. Long working hours and occupational stress-related cardiovascular attacks among middle-aged workers in Japan. J Human Ergol. 1991;20:147-53.

5. Van der Hulst M. Long workhours and health [review]. Scand J Work Environ Health. 2003;29(3):171-88.

6. Spurgeon A, Harrington JM, Cooper CL. Health and safety problems associated with long working hours: a review of the current position. Occup Environ Med. 1997;54:367-75.

7. Dembe AE, Erickson JB, Delbos RG, Banks SM. The impact of overtime and long work hours on occupational injuries and illnesses: new evidence from the United States. Occup Environ Med. 2005;62:588-97.

8. Dong X. Long workhours, work scheduling and work-related injuries among construction workers in the United States. Scand J Work Environ Health. 2005;31(5):329-35.

9. Härmä M. Workhours in relation to work stress, recovery and health [review]. Scand J Work Environ Health. 2006; 32(6, special issue):502-14.
10. Beckers DGJ, Van der Linden D, Smulders PGW, Kompier MAJ, Van Veldhoven MJPM, Van Yperen NW. Working overtime hours: relations with fatigue, work motivation, and the quality of work. J Occup Environ Med. 2004;46:1282-9.

11. Taris TW, Beckers DGJ, Verhoeven LC, Geurts SAE, Kompier MAJ, Van der Linden D. Recovery opportunities, work-home interference, and well-being among managers. Euro J Work Organ Psychol. 2006;15(2):139-57.

12. Beckers DGJ, Van der Linden D, Smulders PGW, Kompier MAJ, Taris TW, Van Yperen NW. Distinguishing between overtime work and long work hours among full-time and part-time workers. Scand J Work Environ Health. 2007; 33(1):37-44.

13. Kompier MAJ. New systems of work organization and workers' health. Scand J Work Environ Health. 2006;32(6, special issue):421-30.

14. Tucker P, Rutherford, C. Moderator of the relationship between long work hours and health. J Occup Health Psychol. 2005;10(4):465-76.

15. Van der Hulst M, Geurts S. Associations between overtime and psychological health in high and low reward jobs. Work Stress. 2001;15:227-40.

16. Van der Hulst M, Van Veldhoven M, Beckers D. Overtime and need for recovery in relation to job demands and job control. J Occup Health. 2006;48:11-9.

17. Geurts SAE, Sonnentag S. Recovery as an explanatory mechanism in the relation between acute stress reactions and chronic health impairment. Scand J Work Environ Health. 2006;32(6):482-92.

18. Meijman TF, Mulder G. Psychological aspects of workload. In: Drenth PJD, Thierry H, de Wolff CJ, editors. Handbook of work and organizational psychology. 2nd ed. Hove (United Kingdom): Psychology Press/Erlbaum (UK) Taylor \& Francis; 1998. p 5-33.

19. Sparks K, Cooper C, Fried Y, Shirom A. The effects of hours of work on health: a meta-analytic review. J Occup Org Psychol. 1997;70:391-408.

20. Bolger N, Davis A, Rafaeli E. Diary methods: capturing life as it is lived. Ann Rev Psychol. 2003; 54:579-616.

21. Semmer N.K., Grebner S, Elfering A. Beyond self-report: using observational, physiological, and situation-based measures in research on occupational stress. In: Perrewé PL, Ganster DC, editors. Research in occupational stress and well-being: emotional and physiological processes and positive intervention strategies. Amsterdam: Elsevier; 2004:205-63.

22. Van Hooff MLM, Geurts SAE, Taris TW, Kompier MAJ. Work-home interference: how does it manifest itself from day to day? Work Stress. 2006;20(2):145-62.

23. Van Hooff MLM, Geurts SAE, Kompier MAJ, Taris TW. Workdays, in-between workdays, and the weekend: a diary study on effort and recovery. Int Arch Occup Environ Health. 2007;80(7):599-613.

24. Karasek RA, Pieper CF, Schwartz JE. Job Content Questionnaire and user's guide: revision 1.1. Los Angeles (CA): University of California; 1985.

25. Van Veldhoven M, De Jonge J, Broersen S, Kompier M, Meijman T. Specific relationships between psychosocial job-conditions and job-related stress: a three level analytic approach. Work Stress. 2002;16:207-28.

26. Michielsen HJ, De Vries J, Van Heck GL. Psychometric qualities of a brief self-rated fatigue measure: the fatigue assessment scale. J Psychosom Res. 2003;54: 345-52.

27. Rothbard NP. Enriching or depleting? the dynamics of engagement in work and family roles. Adm Sci Q. 2001;46:655-84. 
28. Raudenbusch SW, Bryk AS. Hierarchical linear models applications and data analysis methods. New York (NY): Sage Publications Inc; 2002.

29. Hox J. Multilevel analysis: techniques and applications. Mahwah (NJ): Lawrence Erlbaum Associates; 2002.

30. Karasek R. Demand/control model: a social, emotional, and physiological approach to stress risk and active behaviour development. In: Stellman JM, editor. Encyclopedia of occupational health and safety. 4th ed. Geneva: International Labour Office; 1998.

31. Haugland G. An investigation into the effects of working overtime on: a) mental health, b) human performance-a pilot study [master's thesis]. Birmingham (United Kingdom): University of Birmingham; 1996. Cited in: Spurgeon A, Harrington JM, Cooper CL. Health and safety problems associated with long working hours: a review of the current position. Occup Environ Med. 1997;54:367-75.

32. Dahlgren A, Kecklund G, Åkerstedt T. Overtime work and its effects on sleep, sleepiness, cortisol and blood pressure in an experimental field study. Scand J Work Environ Health. 2006;32(4):318-27.

33. Rothbard NP, Edwards JR. Investment in work and family roles: a test of identity and utilitarian motives. Pers Psychol. 2003;56:699-730.

34. Ala-Mursula L, Vahtera J, Kivimäki M, Kevin MV, Pentti J. Employee control over working times: associations with subjective health and sickness absences. J Epidemiol Community Health. 2002;56:272-8.

35. Ala-Mursula L, Vahtera J, Pentti J, Kivimäki M. Effect of employee worktime control on health: a prospective cohort study. Occup Environ Med. 2004;61:254-61.

36. Ala-Mursula L, Vahtera J, Linna A, Pentti J, Kivimäki M. Employee worktime control moderates the effects of job strain and effort-reward imbalance on sickness absence: the 10-town study. J Epidemiol Community Health. 2005;59:851-7.

37. Ala-Mursula L, Vahtera J, Kouvonen A, Väänänen A, Linna A, Pentti J, et al. Long hours in paid and domestic work and subsequent sickness absence: does control over daily working hours matter? Occup Environ Med. 2006; 63:608-16.

38. Hughes EL, Parkes KR. Work hours and well-being: the roles of work-time control and work-family interference. Work Stress. 2007;21(3):264-78.

39. Golden L, Wiens-Tuers B. Mandatory overtime work in the United States: who, where, and what? Labor Stud J. 2005;30:1-26.

40. Golden L, Wiens-Tuers B. To your happiness?: extra hours of labor supply and worker well-being. J Socio-Economics. 2006;35:382-97.

41. Rissler A, Elgerot A. Stress reactions during overtime work. Stockholm: Department of Psychology, Stockholm University; 1978. Report 23. Cited in: Dahlgren A, Kecklund G, Åkerstedt T. Overtime work and its effects on sleep, sleepiness, cortisol and blood pressure in an experimental field study. Scand J Work Environ Health. 2006;32(4):318-27.

42. Åkerstedt T. Psychosocial stress and impaired sleep. Scand J Work Environ Health. 2006;32(6, special issue):493-501.

43. Siegrist J, Rödel A. Work stress and health risk behaviour. Scand J Work Environ Health. 2006;32(6, special issue):47381.

44. Beckers DGJ, Van der Linden D, Smulders PGW, Kompier MAJ, Taris TW, Geurts SAE. Voluntary or involuntary?: control over overtime and rewards for overtime in relation to fatigue and work-satisfaction. Work Stress. 2008;22:33-50.

Received for publication: 24 May 2007 